\title{
Montoneras andinas, violencia ritual y saqueos: el caso de los rebeldes de Huánuco (1811-1812)*
}

\section{Marissa BaZán-Díaz}

Afiliada institucionalmente a la Universidad de Lima (Perú).Correo electrónico: mbazand@ulima.edu.pe. La autora es Magíster en Historia por la Universidad Nacional Mayor de San Marcos (Perú). Entre sus publicaciones recientes esta: "El impacto de los panfletos y los rumores en la rebelión de Huánuco, 1812: Los Incas y la interpretación hecha en el caso de Juan de Dios Guillermo" En: El Perú en revolución. Independencia y guerra: un proceso, 1780-1826, (eds.) Manuel Chust y Claudia Rosas (España: Universidad Jaume I; México: Universidad de Michoacán, Perú: PUCP, 2017). Entre sus temas de interés se encuentran Historia política, Etnohistoria andina, Proceso de Independencia del Perú, Sectores populares indígenas y Rebeliones andinas.

\footnotetext{
Recibido: 29 de marzo de 2019

Aprobado: 10 de noviembre de 2019

Modificado: 20 de noviembre de 2019

Artículo de investigación científica
}

DOI: http://dx.doi.org/10.15648/hc.36.2020.7

\footnotetext{
* Este artículo forma parte del segundo capítulo de la tesis de maestría "La participación de los sectores subalternos en la rebelión de Huánuco, 1812: Saqueadores e incanistas" presentada en la Universidad Nacional Mayor de San Marcos (Perú). Financiación propia.

Esta publicación está bajo una licencia Creative Commons Reconocimiento-NoComercial 4.0
} 
Montoneras andinas, violencia ritual y saqueos: el caso de los rebeldes de Huánuco (1811-1812)

\title{
Resumen
}

El presente trabajo tiene como objetivo central, analizar el desempeño de las montoneras andinas, que en 1812, lograron instalar una junta de gobierno en Huánuco. Las acciones violentas en esta rebelión no sólo significaron desorden y barbarie, sino que tuvieron un papel simbólico, que provenía de una racionalidad ritual, expresada principalmente, a través de los saqueos. Sin soslayar el papel que tuvieron los ejércitos criollos en el proceso de independencia americana, este enfoque permite visibilizar la activa participación y el liderazgo indígena durante la fase regional de ese proceso, rumbo a la construcción de los nuevos Estados.

Palabras clave: Proceso de independencia del Perú, participación regional, montoneras andinas, violencia ritual simbólica, indígenas, saqueos

\section{Andean "montoneras", ritual violence and looting: the case of the Huánuco rebels (1811-1812)}

\begin{abstract}
The main objective of this work is to analyze the performance of the Andean mountains, which in 1812, managed to install a government junta in Huánuco. The violent actions in this rebellion not only meant disorder and barbarism, but they also had a symbolic role, which came from a ritual rationality, expressed mainly through looting. Without ignoring the role that the Creole armies had in the process of American independence, this approach makes it possible to make visible the active participation and indigenous leadership during the regional phase of that process, towards the construction of the new States.
\end{abstract}

Key words: Process of independence of Peru, regional participation, Andean mountains, symbolic ritual violence, indigenous people, looting.

\section{Os militares andinas, violência ritual e pilhagem: o caso dos rebeldes de Huánuco (1811-1812)}

Resumo

O principal objetivo deste trabalho é analisar o desempenho das montanhas andinas, que em 1812 conseguiram instalar uma junta do governo em Huánuco. As ações 
violentas dessa rebelião não apenas significaram desordem e barbárie, mas também tiveram um papel simbólico, que veio de uma racionalidade ritual, expressa principalmente por meio de saques. Sem ignorar o papel que os exércitos crioulos tiveram no processo de independência americana, essa abordagem possibilita tornar visível a participação ativa e a liderança indígena durante a fase regional desse processo, na direção da construção dos novos Estados.

Palavras-chave: Processo de independência do Peru, participação regional, montanhas andinas, violência ritual simbólica, povos indígenas, saques.

\section{Montoneras andines, violence rituelle et pillages: le cas des rebelles de Huánuco (1811-1812)}

\section{Résumé}

L'objectif principal de ce travail est d'analyser les performances des montagnes andines qui, en 1812, ont réussi à installer une junte gouvernementale à Huánuco. Les actions violentes de cette rébellion ne signifiaient pas seulement le désordre et la barbarie, mais elles avaient également un rôle symbolique, qui provenait d'une rationalité rituelle, exprimée principalement par le pillage. Sans ignorer le rôle des armées créoles dans le processus d'indépendance américaine, cette approche permet de rendre visible la participation active et le leadership indigène pendant la phase régionale de ce processus, vers la construction des nouveaux États.

Mots clés: Processus d'indépendance du Pérou, participation régionale, montagnes andines, violence rituelle symbolique, populations autochtones, pillages.

\section{INTRODUCCIÓN}

La historiografía peruanista sobre la independencia tuvo un interesante debate acerca de si fue ¿conseguida, concedida o concebida? Este hecho, además, abrió paso al cuestionamiento de la fecha oficial elegida para conmemorarla, 28 de julio de 1821, la cual no convence a todos ${ }^{1}$. Para

1 Dicha polémica fue muy notoria en la década del 70s y 80s, con la publicación del artículo de Heraclio Bonilla y Karen Spalding (1972), donde señalaron que ésta fue concedida gracias a las victorias de los ejércitos criollos libertadores. Frente a esto el artículo de Scarlett O'Phelan (1985) consideró como un mito a dicha propuesta porque solo había considerado la lógica criolla capitalina (centra- 
un grupo importante de historiadores elección de esta fecha partió del preponderante centralismo limeño. Incluso aún hoy, respaldados por la tesis de "la independencia concedida", la cual señala que ésta se produjo gracias a la llegada de los ejércitos libertadores extranjeros, liderados por San Martín y Bolívar, quienes la impusieron a "los peruanos" -o mejor dicho a los criollos limeños-, por lo que en el Perú esta decisión fue tardía, a diferencia de otros ${ }^{2}$. Sin embargo, esta propuesta ocultaba la idea que ya desde antes se había realizado levantamientos e incluso "gritos de independencia", pero en las regiones, con una importante participación de indios y mestizos ${ }^{3}$; y que la lucha por la separación del yugo español, fue un proceso que no tiene en realidad una fecha exacta de inicio, así como tampoco a un solo grupo social protagonista ${ }^{4}$.

Justamente, este artículo tiene como objetivo principal, contribuir a darle presencia a las provincias, a partir de las acciones de los rebeldes indígenas en Huánuco en 1812, considerando que la independencia fue un proceso que tuvo dos etapas5: La primera fue de carácter regional, con levantamientos dirigidos por la población del virreinato, desde el temprano siglo XIX, actuando principalmente mediante montoneras. Un segundo momento, de carácter continental, con la llegada de San Martín y Bolívar que completaron el proceso de la independencia en el Perú, a través de la formación de ejércitos apoyados por guerrillas y montoneras. Considerando esta cronología, se buscará resaltar a la primera, destacando el papel de los indígenas, a contracorriente de la

lismo limeño) sin tener presente a la vertiente regional e indígena. Ampliar en: Carlos Contreras y Luis Miguel Glave (editores), La independencia del Perú. ¿Concedida, conseguida, concebida? (Lima: Instituto de Estudios Peruanos, 2015).

2 A partir del año 2009 la mayoría de países de Hispanoamérica han conmemorado sus bicentenarios de independencia a diferencia del Perú que recién lo hará en el 2021.

3 Los casos de los gritos de independencia, previo a Lima, en Trujillo, Huaura, entre otros, son representativos; así como los levantamientos en Tacna, Huánuco y Cuzco contra las autoridades españolas. En ese sentido, el concurso organizado por la historiadora Cecilia Méndez tuvo como afán el cuestionar la fecha oficial del bicentenario peruano. Ver: https://www.youtube.com/watch?v=VQBRsb6Rc5Q (09/03/14).

$4 \quad$ Virgilio Roel (1988), llegó a plantear que los peruanos como Túpac Amaru II, en 1781, iniciaron la independencia para luego convertirse en una "revolución secuestrada" por la participación de agentes foráneos y criollos.

5 Esta cronología fue tomada de: Scarlett O'Phelan, "El mito de la "independencia concedida"”, Histórica Vol. 9 No. 2 (1985): 191. http://revistas.pucp.edu.pe/index.php/historica/article/view/8222 (28/08/2016), 191. 
mayoría de investigaciones que se concentran en el desempeño criollo durante este proceso.

Un segundo objetivo es demostrar la participación activa que tuvieron los indígenas mediante las montoneras, una organización armada cuya mayor actuación fue previa a la llegada de los ejércitos libertadores e integrada por un sinnúmero de individuos, carentes de instrucción militar. Por esta razón, sus ataques se realizaban sin estrategias, la minoría de sus miembros, utilizaba sables y fusiles, pero la gran mayoría, se agenciaba de lanzas, palos, hondas y otros rudimentarios instrumentos. Sus maniobras las ejecutaban de manera repentina y en desorden o "de a montón"; de allí su denominación. Sus líderes fueron alcaldes, curacas, sacerdotes, oficiales y hasta algunos hacendados. Cuando los levantamientos concluían, retornaban a sus pueblos para continuar con sus labores cotidianas, puesto que no eran militares de oficio ${ }^{6}$. Precisamente, estudiar a esta forma de organización armada -que tuvo entre sus filas a una gran cantidad de indios- resulta revelador porque demuestra la forma cómo contribuyeron en el proceso de construcción de una nueva época política en el Perú, teniendo como guía el enfoque weberiano, el cual les reconoce la capacidad de autonomía a cualquier grupo social en sus acciones frente a diversas situaciones políticas ${ }^{7}$.

6 Hacia la época de 1821 a 1824, la mayoría de montoneros comenzaron a ser absorbidos por las guerrillas, por lo que tuvieron mayor actuación entre 1800 a 1820. Véase: Cristóbal Aljovín, Caudillos y constituciones: Perú, 1821-1845 (Lima: PUCP/Instituto Riva-Agüero / Fondo de Cultura Económica, 2000), 21-196; Scarlett O'Phelan, Kurakas sin sucesiones: del cacique al alcalde de indios (Perú y Bolivia 1750-1835) (Cusco: Centro de Estudios Regionales Andinos Bartolomé de las Casas, 1997), 60-62; Gustavo Vergara, Montoneras y guerrillas en la etapa de la emancipación del Perú, 1820-1825 (Lima, 1973), 203-207. Además, existe comúnmente una confusión entre montoneras y guerrillas, sin embargo, esta última se conformó por un número reducido de individuos, entre 15 y 30, llamados guerrilleros, los cuales se caracterizaban por su rápida movilidad al hacer uso de caballos y mulas; su arma principal fue la lanza, aunque algunos portaban fusiles y sables; sus ataques fueron obedeciendo al factor sorpresa embistiendo mediante la retaguardia o utilizando la táctica de la emboscada con la finalidad de interrumpir el avance realista al apropiarse de sus víveres y ganado; y contaron con un manual de instrucción marchando detrás de los ejércitos; características distintas a la de las montoneras que actuaron de manera más descontrolada y espontánea. Consulte: Cecilia Méndez y Carla Granados, "Las guerras olvidadas del Perú: formación del estado e imaginario nacional" en Rev. Sociol. Polít., Curitiba, Vol. 20 No. 42 (2012), http://www.scielo.br/pdf/rsocp/v20n42/06.pdf (28/06/2013).

7 Max Weber, Economía y sociedad, $3^{a}$ ed. (México: FCE, 2014), 1071-1382. 
El tercer objetivo de este trabajo es complementar el conocimiento acerca de las causas que llevaron a la población huanuqueña a organizar las montoneras. La intención es ir más allá del análisis económico y político, y más bien aportar en la reflexión acerca de la naturaleza de las acciones violentas. De esta manera, se plantea que la decisión de optar por la insurgencia no representó sólo un conjunto de acciones bélicas "propias de bárbaros" guiados por la desesperación, sino que fue impulsada debido a que la situación que se vivía había traspasado el límite de su tolerancia. El ambiente de injusticia, había convertido a la violencia en un instrumento, mediante el cual, imaginaron encontrar una salida rápida para mejorar su situación. Esta lógica, probablemente, fue alentada por las experiencias previas, como la rebelión de Túpac Amaru II y los levantamientos en Huánuco, anteriores a $1812^{8}$. En segundo lugar, tomando en cuenta las propuestas de la antropología, se puede señalar que la violencia rebelde -desarrollada en acciones como los saqueos, robos, cánticos, bebidas y bailes-, tuvo un sentido de ritualidad simbólica y no fue producto del alcohol y el caos ${ }^{9}$. Realizar el análisis bajo esta perspectiva, permitirá darle una interpretación a su actuación, más allá de los documentos escritos -puesto que la mayoría indígena era ágrafa- encontrándole un sentido a las acciones violentas de las montoneras y no sentenciarlas como irracionales.

8 Mi perspectiva sobre la violencia se basa en la propuesta de Charles Tilly, Louis Tilly y Richard Tilly, El siglo rebelde, 1830-1930 (España: Prensas Universitarias de Zaragoza, 1997), 331-333. Ahora bien, para el caso de Huánuco no sólo los levantamientos foráneos influenciaron en su ánimo de formar montoneras, también dentro, antes de 1812, se contó con la experiencia de levantamientos contra los abusos de las autoridades españolas. De esta manera, tenemos en 1777 el alzamiento de los humalianos en Llata y en 1782, Huallanca. Véase: Ella Dunbar Temple, "Prólogo", en Colección Documental de la Independencia del Perú, Vol. 1 (Tomo III) (Lima: Comisión Nacional del Sesquicentenario de la Independencia del Perú, 1971) XLVII; José Varallanos, Historia de Huánuco. Introducción para el estudio de la vida social de una región del Perú. Desde la época prehistórica hasta nuestros días (Buenos Aires: Imprenta López, 1959), 444-445.

$9 \quad$ Es importante considerar que: "Los fines del ritual guardaran relación abierta e implícitamente con las circunstancias antecedentes y a la vez ayudaran a determinar el sentido de los símbolos. Luego hay que estudiar los símbolos en el contexto concreto de ese ritual." Véase: Víctor Turner, La selva de los símbolos. Aspectos del ritual Ndembu (México: Siglo XXI editores, 1999), 50. Además, se debe considerar las herencias del pasado como la propuesta de Qhapaq Hucha de la época incaica, donde "el sacrificio" de personas simbolizaban las alianzas militares y/o el advenimiento de buenas cosechas; convirtiéndose estas acciones violentas en instrumentos para lograr objetivos. Consulte: Thurner, Mark, "Guerra andina y política campesina en el sitio de La Paz, 1781" en Poder y violencia en los andes, eds. Henrique Urbano y Mirko Lauer (Cusco: Centro de Estudios Regionales Andinos Bartolomé de Las Casas, 1991), 93-121. 


\section{El aVANCE de laS MONTONERAS: LA CONVOCATORIA E INICIO DE LA VIOLENCIA}

La rebelión de Huánuco de 1812 tuvo como principales causas, las disposiciones borbónicas procedentes de Lima de índole económica que prohibieron la venta de tabaco y de productos agrícolas, afectando a los criollos e indios respectivamente, y el favoritismo político a los lugareños "europeos", especialmente a la familia Llanos, provocando al hartazgo de la población ${ }^{10}$. El cura Jadó, al respecto declaró: "El Pueblo clamava por tan injustas usurpaciones, y en los 6 años que conozco Huanuco he oido una queja continua en este asunto señalando los vecinos y Comunidades que se ven sin sus fincas por las usurpaciones de los Llanos..."11, este testimonio manifiesta que las quejas llevaban tiempo sin intención de ser cambiadas por parte de las autoridades, como el subdelegado García, convirtiéndose la rebelión en una opción inevitable para logra dichos cambios.

Previamente a su inicio, circularon una gran cantidad de rumores con la finalidad de denunciar los abusos de las autoridades, anunciar el desborde de la violencia y, sobre todo, convocar a la población para la formación de las montoneras, atrayendo a miles de indios, quienes, junto a otros grupos sociales, tomaron el 22 de febrero el puente de Huayaupampa, iniciándose una oleada de saqueos y asesinatos en Huánuco, Ambo, Llata, entre otros pueblos ${ }^{12}$. Precisamente, el agustino Duran Martel, el 18 de febrero redactó una misiva de convocatoria para formar las montoneras:

10 Ella Dunbar, "Prólogo", XXXVIII; Luís Glave, "Cultura política, participación indígena y redes de comunicación en la crisis colonial. El Virreinato Peruano, 1809-1814”, Historia mexicana LVIII (1), Julio-setiembre (México: El Colegio de México, 2008), 392.

11 Nueva Colección Documental de la Independencia del Perú (NCDIP), (Lima: Universidad Peruana de Ciencias Aplicadas (UPC), Congreso de la República, Fondo Editorial del Congreso del Perú, Asociación por la Cultura y la Educación Digital (ACUEDI), Fundación M. J. Bustamante de la Fuente, Red INTERINDI, 2018), http://www.acuedi.org/category?id=35 (15/08/2018), Vol. 1: 194.

12 Víctor Peralta, "La participación en las juntas de gobierno peruanas de Huánuco (1812) y Cuzco (1814)", en Entre imperio y naciones. Iberoamérica y el Caribe en torno a 1810, eds. Pilar Cagiao y José María Portillo (España: Universidad de Compostela, 2012), 321; José Varallanos, Historia de Huánuco. Introducción para el estudio de la vida social de una región del Perú. Desde la época prehistórica hasta nuestros días (Buenos Aires: Imprenta López, 1959), 474-475. 
"Amados hermanos nuestros; dense noticia a todos los pueblos con esta misma carta sin demora ni disculpa, para que todos estén aquí a las cuatro de la mañana a una misma hora bien animados con escopetas cargadas, ondas, flechas, sables, rejones, puñales, cuchillos, palos y piedras para acabar con los chapetones de un golpe...porque tienen intención de matarnos a todos nosotros, quitarnos nuestras tierras, chacaras, haciendas y bienes y apoderarse de nuestras provincias...esta carta leerán bien una y otra hasta imponerse bien esto es Panao, Pillao, Acomayo, Churubamba...esta carta bien cerrada no abran delante de mujeres y muchachos sino secretamente con una precaución" ${ }^{13}$.

Como se lee, cuatro días antes del levantamiento se estaba haciendo un llamado a la población, que debía acudir armada con lo que pudieran: instrumentos de fuego, armas punzocortantes y objetos rudimentarios como ondas, flechas, piedras, palos. Además, debían difundir secretamente la convocatoria. Los españoles tomaron cuenta de estos rumores, casi de inmediato, sin embargo, los subestimaron, preocupándose recién cuando se percataron del avance de las montoneras. Frente a estas acciones, el subdelegado García ordenó a un grupo de veinticinco hombres armados -al mando del sargento mayor don Manuel Talancha- detenerlos en el puente Huayaupampa, resultando muertos algunos indios, tres defensores de la ciudad y el alférez de caballería Agustín Pérez, del cual se dijo lo cruzó ebrio ${ }^{14}$. Al día siguiente, viendo que llegaban más indígenas, los españoles peninsulares huyeron, principalmente a Cerro de Pasco; algunos se refugiaron en la casa del criollo don Domingo Berrospi, en conventos e iglesias, siendo el subdelegado García uno de los primeros en retirarse, con la excusa de que estaba yendo a solicitar ayuda al Intendente de Tarma. ${ }^{15}$ Bajo estas circunstancias, se produjo la toma de la ciudad de Huánuco, pero ¿qué significaron estas acciones violentas para las montoneras?

13 Colección Documental de la Independencia del Perú (CDIP), (Lima: Comisión Nacional del Sesquicentenario de la Independencia del Perú, 1975), Tomo III, Vol. 2: 63.

14 Víctor Peralta, "La participación en las juntas de gobierno peruanas de Huánuco (1812) y Cuzco (1814)", 323-324.

15 CDIP, Tomo III, Vol. 1: 266. 


\section{LAS MONTONERAS Y LOS SAQUEOS}

El 23 de febrero -luego del asalto perpetrado sobre el puente Huayaupampa- las montoneras ingresaron a la ciudad de Huánuco, logrando capturarla. Estaban compuestas por aproximadamente 15 mil indios de 13 pueblos, pertenecientes a la Intendencia de Tarma, destacando una mayoría de Panatahuas, integradas principalmente de varones acompañados por sus esposas e hijos ${ }^{16}$. Si bien la invasión fue convocada por los criollos, como el cura Duran Martel, su ejecución sólo fue posible gracias a los líderes indígenas, destacando los alcaldes de las comunidades, los cuales actuaron bajo la figura de capitanes. Del poblado de Panatahuas participaron José Calisto, Mariano Silvestre, José Andrés, Patricio Martínez, Santiago Bautista, Onorato Callán y Valentín Celástico; de Panao, Norberto Aro, quien movilizó a los de Huamalíes; y de Quera, el líder más activo de la toma de la ciudad de Huánuco, José Contreras; entre otro ${ }^{17}$. Su principal objetivo -como señalaron varias declaraciones- fue expulsar a "los europeos", ingresando a la ciudad de manera violenta, a pesar de que los chapetones ya se habían retirado. A la letra:

"Y si los Europeos solo por haber visto a los indios media legua de la Ciudad se penetraron de espanto/, y cobardía, desamparándola todos hasta el mismo Subdelegado y Oficiales Militares, abandonando sus mujeres, hijos, bienes, y posesiones por huyr de la muerte cada instante; metido entre la voracidad de los indios...descaradamente propalaban que concluido el saqueo general, libremente habían de usar de toda mujer. Aquí ya no pudo alcanzar mi sufrimiento, mande...Que todas las niñas se recogiensen a la Yglesia, y del Beaterio que me avisasen... Entre tanto el General Castillo, los secuaces Motinistas y los indios todos los días mas rebeldes, solo trataban de conmover los Pueblos de las

16 CDIP, Tomo III, Vol. 1: 265; 281. Ahora bien, para Fernández (1938) esta cifra es exagerada ya que los que atacaron la ciudad fueron solamente los Panataguas que serían un aproximado de 4 a 5 mil hombres; en cambio para Marie-Danielle Demelas participaron de 1400 a 10000 indios (2003: 211).

17 Carmen Calderón, "La insurrección de Crespo y Castillo del año 1812" (tesis de Doctorado en Historia, Universidad Nacional Mayor de San Marcos - UNMSM, 1978), 197-198; Joelle Chassin, "El rol de los alcaldes de indios en las insurrecciones andinas: Perú a inicios del siglo XIX", Bulletin de I’Institut Francais d’Études Andines 1, No. 37 (2008): 238; Víctor Nieto, Control político, sectores sociales y la revolución de 1812 (Lima: Fondo Editorial Cultura Peruana, 2004), 93-103. 
Provincias inmediatas aglomerando gente y combocandola por medio de cartas seductoras" ${ }^{18}$.

Como se lee, el temor a "la voracidad de los indios" provocó la salida de los Europeos, sin importarles el abandono de sus bienes, hijos y mujeres -estas últimas fueron amenazadas con ser abusadas, por lo que tuvieron que esconderse en las iglesias y el beaterio-, huyendo no solo autoridades como el subdelegado, sino los oficiales militares que se supone debían defender a la ciudad. Esta decisión, evidencia que los vecinos europeos tuvieron una expectativa muy violenta respecto a la entrada de las montoneras, guiados probablemente por el conocimiento de experiencias similares. Bajo esas circunstancias uno de los testigos señaló:

"Que querían registrar las casas de estos (los europeos), y que ningún valiente americano se entrometiese a impedirles amenasandonos con el exterminio...Tubimos que condesender a la entrada de estos insurgentes que nos miraban con las manos atadas, y hechos victimas de su furor, se arrojaron sobre la infeliz ciudad; después de haber empeñado su palabra estos pérfidos, que no harian más que registrar y retirarse: Despues de haber besado la mano a los sacerdotes que casi incados les pedían la guarda de sus propiedades, y después para la mayor seguridad obligaron a don Domingo Berrospi a que tomase sobre si el cargo de Jues, y que en reconocimiento le besaron la mano según su costumbre, olvidaron todo quanto habían prometido quando se hallaron dueños de la ciudad sin la menor resistencia de nuestra parte: sabemos. Señor excelentísimo como explicarnos. Como si fueran unos leones que buscan la presa o como unos condenados que asi mismos se despedazan, poseídos del furor y de la embriagues, cerrando los ojos a las presas sin ver ni la persuasión ni el clamor, empezaron el saqueo de los Mercaderes y de las casas con tan obstinada sequedad que las del Dr. Don Bartolome Bedoya Fiscal del Cusco, la del Subdelegado, y la de los vecinos del mayor vrio (sic) fueron reducidas al polvo. Solo verlas infunde tanto terror y espanto que se hace increíble" ${ }^{19}$.

\footnotetext{
18 CDIP, Tomo III, Vol. 3: 276.
}

19 CDIP, Tomo III, Vol. 1: 282. 
Siguiendo esta declaración, las montoneras, conscientes de la huida de los europeos, prometieron a los vecinos criollos -representados por don Domingo Berrospi- que solo iban a registrar si habían quedado algunos chapetones, pero una vez dentro, iniciaron el saqueo violento de la ciudad, a pesar de que ofrecieron lo contrario, besando incluso las manos de los sacerdotes ${ }^{20}$. Para este declarante lo hicieron como unos "leones" que "se despedazaban" entre ellos, bebiendo alcohol y llenos de furor, considerando a la invasión como terrorífica. Además, anotó que fueron las casas de las autoridades las más golpeadas junto a la de los mercaderes y la de todos los vecinos de "mayor vrio", es decir, los notables. Domingo Berrospi, nos brinda más detalles:

"Entraron conmigo en la ciudad y apenas se vieron en los extramuros quando se desplegaron a correr, gritar y disparar armas tan desconcertadamente, que se embocaron estrepitosamente al Hospicio de la Ciudad y Calle de Mercaderes, donde quebrantando las puertas a pedradas, saquearon y robaron quanto en ellas y las casas habían causado la mayor compasión: Continuó en la noche el saqueo y aun hasta el lunes a las sinco de la tarde...no sesaron un punto de continuar en sus borracheras y latrocinios, hasta que a cosa de las sinco de la tarde vino el común de Chaclla constante de treinta y dos hombres con algunas escopetas y poniéndose a mis ordenes les mande acuartelar..." ${ }^{21}$

Leyendo este testimonio, las montoneras realizaron su ingreso corriendo, gritando, saqueando, robando y disparando, para luego comenzar a destruir la infraestructura -mediante la utilización principalmente de piedras- como las casas mencionadas antes, el hospicio de la ciudad, entre otras edificaciones. Estas acciones violentas duraron dos días, extendiéndose hasta el lunes 24 de febrero a las 5 de la tarde. Complementando esta información, tenemos otra declaración: "Esa misma noche se renovó el saqueo y se violaron los derechos de la propiedad que las casas que habían quedado todavía con algunas serraduras al golpe de las hachas destructoras, quedaron por los suelos extendiéndose estas

20 Los indios no fueron los únicos que efectuaron estos saqueos también participaron mestizos, las castas y hasta criollos de la plebe. Véase: CDIP, Tomo III, Vol. 1: 283.

21 CDIP, Tomo III, Vol. 1: 266. 
hostilidades no solo a los europeos sino a los americanos que creíamos no llegar con vida al 24 siguiente"22. Dicho testimonio corrobora que el saqueo se realizó por varios días y, además, que no solo se emplearon piedras sino también hachas para derribar puertas de aquellas viviendas que al comienzo no pudieron ser saqueadas, siendo incluidas las propiedades de algunos criollos. Además, Berrospi agregó:

“...fue necesario permitirles la entrada que solisitaban para solo buscar a los chapetones y registrar el Hospicio de San Francisco donde aseguravan tenían armas estos, pero esto no solo se redujo a lo que habían propuesto sino que posesionados de la Plaza se echaron al saqueo en tal conformidad que no perdonaron archivo público de papeles, tiendas, ni casas y aun hasta la Real Administración de Rentas... porque su insolencia y barbarismo es tal que nada bueno se puede esperar de ellos y mucho menos sabiendo que vuelven Chapetones objetos de sus iras y desesperación" ${ }^{23}$.

La declaración da cuenta que el motivo del ataque al hospicio se produjo porque las montoneras creían que en este sitio se encontraban las armas de fuego. En cuanto al saqueo contra el archivo público, probablemente se hizo porque allí estaba la documentación legal, fiscal y de deudas que quizás algunos de los rebeldes tenían pendientes, aprovechando las circunstancias para desaparecerlas. Sin embargo, algo que aún no se ha explicado con profundidad, es el porqué de la destrucción de las casas y robos de utensilios de los vecinos españoles -a pesar de no estar presentes-, calificado por varios de los testigos como la evidencia de la irracionalidad imperante. Una primera aproximación, para reflexionar sobre esto, se encuentra en la descripción del ataque perpetrado sobre la iglesia de San Francisco ${ }^{24}$. Al respecto uno de los declarantes señaló:

22 CDIP, Tomo III, Vol. 1: 283.

23 CDIP, Tomo III, Vol. 1: 268.

$24 \mathrm{Al}$ respecto el cura Jadó denunció que fueron saqueados "los archivos del convento y cabildo, robando, e incluso se señala que cometieron violaciones en el beaterio llevados por los efectos del alcohol". Ampliar en: José Varallanos, Historia de Huánuco. Introducción para el estudio de la vida social de una región del Perú, 468-469. 
"Ya se conducían con pausa quando un pelotón de insurgentes que venían semejantes a los santcullotes de la Francia, cometieron el atentado de matar a un paisano con la mayor atrocidad y bolbiendo el exeso del furor a su punto, entraron a la Yglesia de San Francisco cuyo Convento y Templo fue saqueado y profanado solo porque sus religiosos eran Europeos..." 25

De este testimonio, se destaca el calificativo de "santcullotes de la Francia", un término que en la época quería decir pertenecientes a las clases bajas, con prácticas radicales y violentas, lo cual era precisamente lo que estaba ocurriendo. Un segundo asunto interesante es el motivo por el cual asaltaron al convento: los religiosos eran "Europeos". Esto evidencia que el afán de destrucción de las montoneras tenía una lógica. En este caso, saquear este edificio estuvo alentado por el hecho de que los dueños eran los enemigos que deseaban derrotar, llevándolos a no respetarlos, a pesar de ser un recinto eclesiástico, incumpliendo con "su palabra estos pérfidos", como declaraba uno de los testigos ${ }^{26}$. Otras manifestaciones sobre lo sucedido las dijeron el prior fray Pedro Moreno, el cura Ramon Moreno, el agustino fray Villavisencio y el fray Juan de Ordoñes. A la letra:

"Tan embriagados estaban del furor, igualmente que del excesivo licor que tomaron destrosando todas las botijas que encontraron de vino y aguardiente, que no pensaron mas que en arrancar los menajes que en bailar sobre el simulacro de Jesuvhristo, que obligado de esto de estos criminales exesos se puso el Parroco Doctor Don Ramon Moreno a sacar una Procesion de la Ymagen de María Santisima Dolorosa, y al salir fue tal el fervor con que predicó con el fin de apaciguar los que rindieron un tanto a la vehemente insitacion de la verdad." ${ }^{27}$

La declaración da cuenta de cómo las montoneras no detuvieron sus acciones violentas, a pesar de los pedidos del párroco -quien incluso sacó en procesión la imagen de la virgen Dolorosa-, manteniendo sus

25 CDIP, Tomo III, Vol. 1: 282-283.

26 Baldomero Fernández, Huánuco en la revolución de independencia (Lima: Imprenta americana, 1938), 12.

27 CDIP, Tomo III, Vol. 1: 282 
atrocidades, ya que "no pensaron mas que en arrancar los menajes que en bailar sobre el simulacro de Jesuvhristo", lo cual, a juicio de estos testigos, fue debido al "excesivo licor que tomaron" desatando una gran intranquilidad y pérdidas económicas que llegaron a la cifra de un millón de pesos y un saldo de más de treinta muertos ${ }^{28}$. Por su parte el testimonio de Francisco Calero agregó: "Los indios tomaban a los que encontraban, y los hacían ir por delante de ellos de por fuerza, destinando a cada uno de estos sus correspondientes trozos. Algunos, y entre ellos mi parte, viendo que de otra manera no podían librarse del furor de los enemigos, sé que se son malos enemigos; idiotas por naturaleza..."29

Haciendo un balance general, se puede decir que la mayoría de los declarantes consideraron las acciones violentas de las montoneras como consecuencia de la embriaguez, robo, sacrilegio e idiotez; calificativos que incluso ciertos historiadores compartieron en coincidencia con estos testigos, siendo para ellos justamente este comportamiento lo que propició el fracaso de la rebelión ${ }^{30}$. Sin embargo, para no quedarnos solamente con esta versión, la lógica de la ritualidad simbólica, permite darle una interpretación distinta a lo registrado literalmente por las fuentes escritas. Guiados por esta perspectiva, pensamos que la forma de cómo realizaron su entrada, la decisión de la destrucción selectiva de edificios, los saqueos, robos y demás atropellos, tuvieron un rol simbólico, propio de "un modus operandis" utilizado de manera sistemática e influenciado por otros levantamientos indígenas -sobre todo los heredados del siglo XVIII- que aplicaron acciones similares y que tenían como objetivo principal construir una imagen de "victoria" para alentar el avance de las montoneras y conseguir lo que esperaban: destruir a los "Europeos", bajo la lógica, aún, de "viva el rey muera el mal gobierno" y con ello mejorar su situación.

Precisamente, teniendo en cuenta esta perspectiva, es importante analizar por qué los locales, como las casas de los chapetones, "fueron redu-

28 José Varallanos, Historia de Huánuco. Introducción para el estudio de la vida social de una región del Perú, 468-469.

29 CDIP, Tomo III, Vol. 2: 480-483.

30 Ella Dunbar, "Prólogo"; Sebastián Ordoñez, Los precursores olvidados. Gabriel Aguilar y Juan José Crespo y Castillo. Dos semblanzas en dos hechos históricos de la Emancipación (Lima, 1972), 17. 
cidas al polvo", especialmente aquellas pertenecientes a las autoridades, como ocurrió con la del subdelegado García, la del fiscal del Cusco Bartolomé Bedoya y la de "los vecinos del mayor vrio", entre otros. Si bien, fueron atacadas las viviendas de algunos criollos, en el caso de las primeras, se describe que esta acción fue efectuada como si hubiera sido hecha por "leones" terroríficos, describiéndose de esta forma la gran furia con que se castigó a estas propiedades. La siguiente declaración del cura Jadó brinda más detalles:

"Elijieron los yndios de General a Don Domingo pero no con tanta subordinacion que les impidiese el saqueo atroz que empezaron por la casa del Coronel Echegoyen; casa, y tienda del Subdelegado, de Fernandez, y Mejorada como primeros objetos de sus iras. En vano el Cura Moreno quiso contenerlos con procesion, y sermon, todas las casas de los europeos fueron saqueadas aprovechando los yndios solo los caldos y algunos retazos de las tiendas, y los huanuqueños de todo lo de valor. Al saqueo de las casas de los europeos siguieron muchas de criollos dirijiendo las roturas de las puertas los mismos mozos, y mosas de Huanuco que vengavan por mano de los yndios sus particulares agravios. De casas visibles solo las de Berrospi, y sus hijos, y algunos mui pocos se escaparon. El saqueo se hacia de un modo feroz. No solo se sacavan las cosas de valor sino que rompian puertas, ventanas, y quantos muebles de casas hallavan hasta la última ruina" ${ }^{31}$.

Como se lee, los rebeldes pusieron mayor énfasis en los ataques sobre las casas de las autoridades mencionadas, a las cuales se agregaron las del coronel Echegoyen y la de las autoridades de otros pueblos, como la de los subdelegados Fernández y Mejorada, convirtiéndose en "(los) primeros objetos de sus iras", señalando claramente que "todas las casas de los europeos fueron saqueadas" con lo cual, además, se corrobora el motivo de los abusos sobre el convento y templo de la Iglesia de San Francisco, narrado líneas atrás. De esta manera, el aumento de la violencia de sus acciones, fue evidente cuando se trataba de las casas de los "Europeos", en comparación con las propiedades de los criollos -siempre y cuando se trataban de aquellos con fama de ser defensores

31 NCDIP, Vol. 1: 197-198. 
de los peninsulares-, las cuales apenas fueron tocadas. Este tratamiento distinto del saqueo no fue casual, siguiendo esta declaración las montoneras de esta forma "vengavan por mano de los yndios sus particulares agravios", es decir, hay una intención claramente simbólica en estas acciones violentas. Por consiguiente, se hace comprensible que el grado de violencia fue mayor sobre estas viviendas. Las montoneras, con este proceder lograron una forma de "venganza" contra las malas autoridades, pasando dichas casas y edificios a ser su representación simbólica -no olvidemos que los europeos habían huido- por lo que destruirlas, además, era la materialización de sus aspiraciones de "victoria", castigándolos a partir de sus propiedades ${ }^{32}$.

Siguiendo el mismo enfoque, también puedo comprender que cuando los indios "robaron" ganado, herramientas, menajes domésticos, alimentos, tabaco, chocolates, velas, sebos, cuchillos, telas, ropa, espejos, entre otros, a los españoles, dicha actuación fue vista como una manera de "restituir" y acceder a los productos que las autoridades injustas les negaban y "no merecían" 33. Es decir, detrás de estas acciones existió un argumento simbólico de estar haciendo "algo justo" al apropiarse de estos productos, en medio de un tiempo caótico o mundo "al revés", con dueños ausentes. A esto se agregó, innegablemente, el estar bajo los efectos del alcohol y la confusión del saqueo; pero también, las montoneras, probablemente, estaban imaginando que esto se trataba de una muestra -o adelanto- de la mejora de su situación. Por tanto, estas prácticas no solo partieron del afán de aprovecharse de las circunstancias para robar, ya que no todos los rebeldes eran cotidianamente ladrones ${ }^{34}$.

Complementando mis ideas anteriores deseo destacar otra parte de la Complementando estas ideas, la declaración de Jadó, repetida por otros testigos, resulta reveladora: "Los yndios borrachos con los aguardientes que hallaron heran fieras, y no respetaron a su General a quien dieron de

32 La antropología demuestra como las personas tienen proyecciones simbólicas, en este caso a partir de sus propiedades. Véase: Clifford Geertz, La interpretación de las culturas (Barcelona: Gedisa Editorial, 2003), 358.

33 Ella Dunbar, "Prólogo", XXXVIII; LVII

34 Las cosas arrebatadas fueron en grandes cantidades. Ampliar información al respecto en: CDIP, Tomo III, Vol. 3: 511-566. 
palos por que quiso impidir alguno de sus desordenes. Duró el saqueo la tarde y noche del 23, y hasta el medio dia del 24"35. Para entender mejor este testimonio, es necesario recordar que todo ritual suele estar acompañado de actos festivos y como hemos venido diciendo, la violencia usada por las montoneras, involucró ritualidad, expresada por sus acciones simbólicas. Bajo ese sentido, se hace entendible que luego de la toma de la ciudad, mediante los saqueos, lo que siguió fue la organización de bailes, el consumo de bebidas alcohólicas, como el aguardiente, llevándose a cabo una fiesta "sobre el simulacro de Jesuvhristo". En realidad, al igual como en el caso de los saqueos y robos, estas acciones festivas contenían un significado, en este caso, el de celebrar "la victoria simbólica" sobre los enemigos europeos ausentes y no exclusivamente porque se trataban de individuos borrachos y desenfrenados.

Por tanto, el enfoque de violencia ritual simbólica, muestra que las montoneras no actuaron así por el simple hecho de ser saqueadores, ladrones, idiotas, bárbaros, alcohólicos, entre otros calificativos, sino que partió de una lógica propia que los llevó a rebelarse de esta manera. Esta forma de llevar a cabo sus acciones, les brindó una esperanza de lograr el triunfo sobre las autoridades y sus enemigos "los Europeos". Por consiguiente, si bien el fragor caótico de la rebelión, conjuntamente con el consumo de bebidas alcohólicas, contribuyó a los hechos violentos, no los originaron como suele creerse, convirtiéndose estos actos en su complemento. Además, les brindó una expectativa de victoria simbólica, celebrando las acciones exitosas porque los "chapetones objetos de sus iras y desesperación" estaban siendo destruidos y castigados, ejecutando su venganza sobre estos objetos materiales.

\section{LÍDERES INDÍGENAS DE LAS MONTONERAS Y LOS SAQUEOS}

Teniendo en cuenta que la violencia de tipo ritual simbólico marcó las acciones de las montoneras, se analizará, ahora, la participación de los indios que actuaron -a diferencia de los criollos como el cura Duran Martel, ideólogo de la rebelión- ${ }^{36}$ como los líderes y ejecutores del in-

35 NCDIP, Vol. 1: 197-198.

36 La mayoría de estudios sobre la rebelión de Huánuco se concentran en el liderazgo de criollos, como 
greso de los rebeldes, a los diversos pueblos de vecinos europeos. Justamente, la declaración del alférez real don Manuel Berrospi, nos da cuenta de uno de ellos, reconocido por el propio virrey Abascal como el más importante capitán ${ }^{37}$ :

"Don Bernardino Cáceres de mi orden a cosa de las ocho de la mañana aprehendió a José Contreras sugeto motor de tumulto, pues además del acendente que tenía con los indios, les inducía a que cometiesen desordenes inauditos, señalándoles las casas de los mas pudientes para quebrantar las puertas y saquearlas, y a mayor abundamiento el mismo por su propia boca quando lo reprehendían hacia mal en sus operaciones, asegurava públicamente que era cabeza de motín de esta general sublevación, y que los indios hacían quanto él quería: Esto lo bociferó muchas veces, de manera que todo el público se hizo capaz de atestiguarlo. Este revoltoso o motinista ha sido causa de las inquietudes como ha padecido el público..." 38 .

Como se lee, el declarante identificó al indio José Contreras, alcalde de Quera, como el "sugeto motor del tumulto", autoproclamado "cabeza de motin", el cual contó con la capacidad de movilizar a los indios montoneros, convirtiéndolos en saqueadores. Además, según este documento, él fue el que dio las órdenes de la forma cómo atacarían, "señalándoles las casas de los mas pudientes para quebrantar las puertas y saquearlas", sin respetar los ruegos de su hijo Domingo Berrospi, quien con bandera blanca pidió no arremetan en ellas ni en la de los curas. Este testimonio fue ratificado por el teniente de milicias don Antonio de Zavala, quien dijo: "José Contreras los volvió a traer, y les hizo renovar el saqueo mas horroroso. Este cholo el mas encarnizado contra todos los blancos no pudo ser contenido por respeto ni razón, y tratando yo de aquietarlo con buenas palabras desde la casa de Berrospi, me increpo muchas veces, y me ofrecio traspasarme con una espada llamándome traidor" ${ }^{\prime 39}$. Por tanto, la forma cómo ingresaron a la ciudad

Crespo y Castillo y en el papel de los curas, por lo que este trabajo buscó darles más protagonismo a los indígenas.

37 CDIP, Tomo III, Vol. 1: 96.

38 CDIP, Tomo III, Vol. 1: 267.

39 CDIP, Tomo III, Vol. 1: 390. 
las montoneras, no fue espontánea, es decir, producto del desorden e irracionalidad, el atacar a edificios específicos con mayor furia estuvo fijado como forma de entrada, gracias a las órdenes de sus líderes, en este caso el indio Contreras -incluso antes de haber ingerido alcohol, por lo menos no una gran mayoría, como sí ocurrió una vez que capturaron la ciudad- para luego dar pase a la fiesta de la celebración de "victoria simbólica" del levantamiento.

En paralelo, el 26 de febrero se enteró de la rebelión el intendente Gonzales Prada y el 2 de marzo, el virrey Abascal, quien aprobó las medidas que se aplicarían para detener el avance de dichas montoneras. Mientras tanto, en Huánuco, se convocó un cabildo para constituir un gobierno provisional o Junta, la cual juró en nombre del "Augusto rey y Cortes que nos gobiernan"; informándose de dicha decisión al virrey, a través de una misiva, justificando que ésta se había creado por el vacío del poder provocado por la huida del subdelegado García. ${ }^{40}$ Además, se nombró "como Subdelegado a Don Domingo Berrospi; por Alcalde de Segundo Voto a don Juan José Ruiz, Síndico Procurador General a don Juan José Crespo y Castillo...", ${ }^{41}$ asistiendo a la ceremonia de su instalación los curas, "varios vecinos de honor" y los indios, entre otros. Debemos destacar que la formación de esta Junta fue gracias a que los rebeldes tomaron la ciudad, por lo que la participación de las montoneras resultó un hecho clave y no sólo la actuación de los dirigentes criollos $^{42}$.

Ahora bien, el jefe de la junta, don Domingo Berrospi, terminó traicionando a los rebeldes por dos razones: primero, porque mandó apresar

40 Ella Dunbar, "Prologo", XXX-XXXI; Baldomero Fernández, Huánuco en la revolución de independencia, 16; Scarlett O'Phelan, "Abascal y el fantasma de las revoluciones" en Abascal y la contraindependencia de América del Sur, eds. Scarlett O’Phelan y Georgés Lomné (Lima IFEA/ Fondo Editorial PUCP, 2013), 240.

41 José Varallanos, Historia de Huánuco. Introducción para el estudio de la vida social de una región del Perú, 470; Sebastián Ordoñez, Los precursores olvidados, 110. Más datos sobre la biografía de Crespo y Castillo lo pueden encontrar en: César García, Dos precursores de la Independencia Nacional. 1805-1812. (Lima: Editorial Minerva, 1973), 54-56.

42 No olvidemos que en otros países de América hispana tanto las protestas contra las reformas borbónicas como la formación de juntas en la época de las cortes de Cádiz, consignó las fechas fundacionales de sus independencias a diferencia del Perú. 
al líder indígena, José Contreras, bajo el argumento de ser el responsable del saqueo y, como supuestamente la cárcel de la ciudad no era un lugar seguro, lo envío a su hacienda Andabamba, lugar donde fue asesinado, ahogándolo con un cordel sobre un chirimoyo, partiéndole las canillas con "una caxuela"-para sacarle los grilletes que tenía puesto-, para luego lanzar su cuerpo al río Huallaga ${ }^{43}$. No satisfecho con esta traición, en segundo lugar, Berrospi, informó, al intendente Gonzales Prada, sobre los preparativos que las montoneras estaban organizando, para enfrentar de manera sorpresiva a los militares realistas, señalándole el lugar desde dónde atacarían, unos "quince mil" indios, en Ambo.

Las montoneras, especialmente los alcaldes, enteradas de estas dos acciones, lo acusaron de traidor y lo destituyeron, reemplazándolo por otro miembro de la Junta. Así, el 2 de marzo se produjo el nombramiento como "General Jefe Político y Militar de la Revolución” de José Crespo y Castillo, en la plaza de armas, con el respaldo de diez mil indios, según manifestó en su declaración. ${ }^{44}$ De esta manera, la muerte del capitán indígena José Contreras habría sido uno de los factores que posibilitó el ascenso de Crespo y Castillo, el personaje criollo más recordado por la mayoría que toma cuenta sobre esta rebelión. Sin embargo, es evidente que esto no fue buscado por su propia voluntad, por lo que su liderazgo fue circunstancial. También, demuestra que las acciones violentas, empleadas por las montoneras -las cuales en algunos momentos sí se volvieron caóticas-, no fueron las únicas que le jugaron en contra a la causa rebelde, como algunos historiadores habían señalado. La traición de criollos como Berrospi, la falta de un liderazgo comprometido y el carente arsenal bélico, contribuyeron a su caída. Más bien, las acciones violentas, cargadas de ritualidad simbólica, sirvieron como elementos de cohesión y aliento para continuar con el levantamiento, forjando una figura de "victoria simbólica", que aparte de expresar el afán del castigo, logró atraer a más rebeldes, entusiasmados por lograr el triunfo. de Pedro Rodríguez. Ampliar en: José Varallanos, Historia de Huánuco. Introducción para el estudio de la vida social de una región del Perú, 470-486; Sebastián Ordoñez, Los precursores olvidados, 113 Ella Dunbar, "Prólog", XXXI. 
Ahora bien, Huánuco no fue el único lugar donde se produjeron saqueos, robos y celebraciones. En ese sentido, la Junta, estando ahora bajo el liderazgo de Crespo y Castillo, convocó a todos los varones de 12 años de edad, en adelante, a formar parte de las montoneras, para poder llevar a cabo la toma de otros pueblos pertenecientes a la Intendencia de Tarma. También, se logró obtener dos cañones de maguey y cien escopetas ${ }^{45}$. Bajo estas circunstancias, se organizó el primer combate de Ambo, lugar donde estaban atrincherados los europeos, siendo conducidos por el mestizo José Rodríguez, nombrado comandante de las huestes y apoyado por los diversos capitanes indios, como Espinoza “el Limeño", José Ulluco, José Mirabal, entre otros ${ }^{46}$. El 5 de marzo, consiguieron hacer huir a los españoles de este poblado, mientras que los que no se unieron al ataque fueron calificados como "traidores a la patria". Este enfrenamiento dejó un saldo de setenta indios muertos, a pesar de esto, las montoneras lograron la victoria ${ }^{47}$.

Tras el triunfo, se produjo el ingreso de los rebeldes a Ambo, dirigidos por el grito de su cabecilla José Rodríguez y los indios montoneros que decían: "viva el rey Fernando Séptimo...muera el mal gobierno", en medio de los repiques de campanas ${ }^{48}$, para enseguida aplicar el saqueo, los asesinatos, la destrucción propiedades -con la ausencia, también, de sus dueños europeos-, donde nuevamente los peores ataques se hicieron sobre las casas de los chapetones e incluso se pretendió incendiar la capilla, porque allí se habrían escondido algunos europeos y por ser el almacén del armamento militar ${ }^{49}$. El cura Jadó, corrobora esta información:

45 José Varallanos, Historia de Huánuco. Introducción para el estudio de la vida social de una región del Perú, 473.

46 NCDIP, Vol. 2: 133

47 Francisco Berroa, Monografía de la Diócesis de Huánuco (1934) (Huánuco, 2012), 19; Baldomero Fernández, Huánuco en la revolución de independencia, 15; Sebastián Ordoñez, Los precursores olvidados, 114-115; Víctor Nieto, Control político, sectores sociales y la revolución de 1812, 103; José Varallanos, Historia de Huánuco. Introducción para el estudio de la vida social de una región del Perú, 472.

48 Víctor Peralta, "La participación en las juntas de gobierno peruanas de Huánuco (1812) y Cuzco (1814)", 324-326

49 José Varallanos, Historia de Huánuco. Introducción para el estudio de la vida social de una región del Perú, 473-474. 
"Las gentes de Huacar ayudó a los yndios a tender la maroma, y unida a ellos entraron todos en Ambo saqueando el Pueblo, matando un criollo herido que quedó alli, y a un bárbaro Catalan que se arrostró a entrar a sacar su silla de montar en medio de todos los yndios con un esmeril con que tumbó 5 ó 6- subiendo la Partida por la cuesta, vió que los yndios arrastraban el cadaver del que quedó muerto primero, y hicieron horrores que no pueden escrivirse. No perdonaron casa alguna, cuyas puertas y hasta los mas viles muebles no hiciesen pedazos, llevandose los avios de montar, y demas que dejaron los europeos en su precipitada fuga." 50

Cuando regresaron de Ambo, las montoneras victoriosas organizaron una nueva fiesta, repicando las campanas y con la organización de una misa de gracia en la plaza. La declaración de José Palomino brinda algunos detalles adicionales:

“...un dia domingo se puso altar en el cementerio, y en el mismo pretil de la plaza, donde se coloco a San Sebastian con Docel, y se selebro Misa Cantada según supo el declarante en honor a la victoria de los indios pues antes y después del Sacrificio se bosiferaba públicamente que se iba a decir Misa de gracias... Que al Regidor Castillo lo llevaron los indios en media en la silla quando correspondia, y que le pusieron una silla grande forrada en terciopelocolorado/, con su cogin del mismo género: Que el estaba con volante, y calzon verde, y que se sentaba den la silla quando correspondia: Que la Misa se celebró a las once, o doce: del dia, y aunque no hubo asistencia formal de vecindario decente, pero que la oyron en grupo toda clase de gentes..." ${ }^{51}$

Según lo descrito, el triunfo de Ambo fue festejado con algarabía por las montoneras, al punto que hicieron una ceremonia, en la cual a Crespo y Castillo se le ofreció una silla y vestimenta a la usanza noble -pero acompañado de los sectores populares porque "no hubo asistencia formal de vecindario decente"-, con el repique de las campanas, la misa cantada, entre otras acciones simbólicas son la finalidad de continuar

\footnotetext{
50 NCDIP, Vol. 1: 200

51 CDIP, Tomo III, Vol. 1: 350-351.
} 
con la lógica de dar la imagen de posible "victoria" -derivado de la violencia y ritualidad- brindando la imagen de que sí era posible lograr los objetivos trazados ${ }^{52}$. Por otro lado, aparecieron nuevos líderes indígenas, los cuales se encargaron de invadir otros pueblos, mediante la aplicación nuevamente del saqueo y la violencia. De esta manera, tenemos el caso del partido de Huamalíes, donde las montoneras fueron convocadas por el Presvitero Don José de Ayala, Ynter del Pueblo de Chupan. Los encargados de su invasión fueron los capitanes Norberto Aro, Vicente Estacio, José Atanacio, José Lucas -quienes primero coordinaron con Berrospi y luego con Crespo y Castillo-, iniciando la insurrección en Pampas. El cura Jadó, declaró lo siguiente:

"Dije a Vuestra Señoría Ylustrísima que en Huamalies, no havia una caveza capaz de dirijir sus pies, y lo confirmo con los pasos que alli se dieron en la insurreccion. Empezó con una ferocidad inaudita, matando a varios de los naturales del pais enterrando viva á una mujer por que les aconsejó se abstubieran de lo que hacian, por las malas resultas que tendria, robando Yglesias, profanando Vasos Sagrados, y ultimamente saqueando varios Pueblos" 53 .

Como se lee, la lógica de los saqueos fue constante, empleando acciones violentas parecidas y teniendo como guías a los líderes indígenas. Los criollos, en cambio, tuvieron muy poca participación en ese sentido, se remitieron a elaborar rumores, especialmente los curas, o a ser parte de la Junta en Huánuco. El indio Norberto Aro, es otro ejemplo de guía para la aplicación del saqueo a la hora de entrar a un pueblo, logrando el 15 de marzo invadir Chupán, donde ordenó actos de violencia similares a los anteriores. También, se encargó de difundir cartas seductoras desde Cani, a los demás pueblos, con la finalidad de alentar a los indígenas a que se unan a las montoneras, teniendo como consigna: "que el destino era ayentar, o matar a los chapetones", para lograr cambiar la situación opresora en la que se encontraban. Sus acciones victoriosas, le valieron para ser reconocido como el capitán de las montoneras organizadas por

52 Roger Vidal, La noche más larga de Huánuco: 22 de febrero de 1812 (Huánuco, 2005), 87-160.

53 NCDIP, Vol. 1: 220 
el poblado de Pachas $^{54}$ y también los de Llata ${ }^{55}$, La ejecución de la toma de estos pueblos, al mando de Aro, fue descrita por el alcalde del pueblo de los Santos Reyes de Cagua, Santiago Espinosa de la siguiente forma:

"Que haviéndose lebantado los ynsurgentes que los del Pueblo de Chupan enterraron viva y quemaron casas, los del Pueblo de Chuquis, Marías y Yanas, arruinaron al Pueblo de Aguamiro... y viendo los distrusos que los ynsurgentes lo hasían con los Pueblos ya mencionados pensé que sería algún mandamiento del Superior, y temiendo los castigos que pueda venir benimos con toda la jente y llegamos al Pueblo de Aguamiro a hunirnos al otro día del saqueo que hicieron los ya sitados Pueblos" $" 56$.

Leyendo este testimonio, se muestra como el saqueo -aparte de ser la forma de cómo se tomaban las ciudades- sirvió para reclutar adeptos, esta vez no apelando a la figura de "victoria simbólica" que incentivó al alistamiento voluntario, sino mediante el "miedo", tal como señala parte de esta declaración: "temiendo los castigos que pueda venir benimos con toda la jente y llegamos al Pueblo de Aguamiro a hunirnos al otro día del saqueo". Por tanto, las montoneras reclutaban a sus miembros, a través de la persuasión y la imposición, ambas fruto de la violencia y la ritualidad simbólica. Para finalizar, sobre la figura de este capitán de montoneras, es importante agregar el detalle de que algunos rebeldes lo denominaron como "Tuma Amaro" o "Tupamaro" -reviviendo el nombre del líder de la más importante rebelión indígena del siglo XVIII- ${ }^{57}$, lo cual permite sustentar la gran probabilidad de conexión entre este alzamiento con la influencia dejada por los levantamientos dieciochescos y entender que sus prácticas y expectativas estuvieron ción para el estudio de la vida social de una región del Perú, 476.

56 NCDIP, Vol. 4: 27

57 NCDIP, Vol. 4: 375-376 
presentes 30 años después, influenciando en Huánuco, Panataguas y Humalíes, en la decisión de optar por la violencia. ${ }^{58}$

De esta manera, los criollos Duran Martel, Berrospi y Crespo y Castillo no fueron los únicos dirigentes, también destacaron los líderes indígenas José Contreras y Norverto Aro, entre otros, quienes guiaron a las montoneras en la toma de los pueblos, mediante los saqueos. A través de dichas acciones, fue posible la instalación de la Junta en Huánuco, ya que la violencia y la ritualidad simbólica sirvió para construir la idea de una posible "victoria", animando a la población a levantarse, por miedo o convicción. Por tanto, el liderazgo de los indígenas junto a las montoneras, contribuyeron en los logros alcanzados por la rebelión, rechazándose la propuesta de que sus acciones provocaron el fracaso. Las montoneras, no fueron simples seguidores de los líderes criollos, carentes de iniciativas y de lógica propia, todo lo contrario, como lo ha demostrado esta investigación.

\section{Desenlace de la Rebelión: "El fracaso" De las montoneras}

El intendente Gonzales Prada, inició la contracampaña marchando sobre Ambo, el 16 de marzo de 1812, acompañado de una importante cantidad de hombres instruidos en armas con refuerzos procedentes de Huariaca. Cuando estaban cerca de Huánuco, fueron notificados, por la Junta, de que si avanzaban serían atacados por 5 mil hombres que formaban parte de las filas montoneras. El intendente haciendo caso omiso a estos mensajes, ordenó la reconstrucción del puente de Huacar y tras lograrlo, se inició el enfrentamiento el 18 de marzo. El resultado fue la derrota de los rebeldes, a pesar de su superioridad numérica, debido a que su actuación fue desordenada y prácticamente sin armas, ya que sólo tenían una escopeta y un cañón de maguey ${ }^{59}$. Además, este segundo encuentro en Ambo fue diferente. En la primera batalla, las montoneras se habían enfrentado a pocos hombres preparados en las armas, lo cual les permitió obtener las iniciales victorias y aplicar sus

$58 \mathrm{Al}$ respecto resulta interesante la propuesta de Víctor Peralta que realiza una reflexión sobre el tema (2012).

59 Joelle Chassin, "El rol de los alcaldes de indios en las insurrecciones andinas: Perú a inicios del siglo XIX”, 239; Víctor Nieto, Control político, sectores sociales y la revolución de 1812, 121-123; 
acciones simbólicas. Sin embargo, ahora, las fuerzas militares estuvieron compuestas por: "600 infantes armados de fusil, 150 lanzas, 100 de caballería con pistola y espadas; 4 cañones de montaña y las correspondientes municiones", brindándole este arsenal la superioridad bélica ${ }^{60}$.

El enfrentamiento dejó un saldo de aproximadamente doscientos cincuenta cadáveres, con un mayor número de muertos y heridos en las filas de los rebeldes, ya que del lado realista solo murió una persona y tuvieron cinco heridos. Producido los hechos, se les ofreció a las montoneras el indulto -si es que deseaban volver a la causa del rey "porque no era guerra entre paisanos"-, lo cual pocos aceptaron, ya que no confiaban en que se cumpliría. Con este triunfo, el 21 de marzo, los españoles lograron retomar la ciudad de Huánuco, siendo recibido el intendente Gonzales Prada por el cabildo, el clero y los prelados. Nuevamente Berrospi, fue el encargado de brindar la bienvenida, dirigiéndose al intendente cargando una bandera blanca, tal como lo hizo con los insurrectos semanas atrás ${ }^{61}$. Tras esto, se inició la captura de los involucrados, lográndose rápidamente, sufriendo el siguiente destino los integrantes de las montoneras ${ }^{62}$ :

Respecto a los indios del común, el fiscal protector de naturales, don Miguel de Eyzaguirre, señaló que se alistaron, en las montoneras, presionados por los abusos de los subdelegados de Huánuco y Panataguas y que "el levantamiento no tuvo otra finalidad que desprenderse de los malos jueces y que todos los daños debían pagar los subdelegados de Huánuco y Panataguas por su mal gobierno." En cuanto a los saqueos, estos fueron considerados como un delito colectivo, ordenando el Intendente, que los rebeldes fueran calificados como "incapaces de

60 Baldomero Fernández, Huánuco en la revolución de independencia, 16-19; Sebastián Ordoñez, Los precursores olvidados, 124-127; José Varallanos, Historia de Huánuco. Introducción para el estudio de la vida social de una región del Perú, 480.

61 Francisco Berroa, Monografía de la Diócesis de Huánuco (1934), 22-23.

62 Estos datos fueron extraídos de: Francisco Berroa, Monografía de la Diócesis de Huánuco (1934), 490; Ella Dunbar, "Prologo", XXXVIII; LXXI; LXV; XLIII; Baldomero Fernández, Huánuco en la revolución de independencia, 19-20; Sebastián Ordoñez, Los precursores olvidados, 129-130; Luís Glave, "Cultura política, participación indígena y redes de comunicación en la crisis colonial. El Virreinato Peruano, 1809-1814", 394. Según el cura Jadó: "los reos principales (fueron ordenados) en tres clases: los que promovieron la revolución, entre ellos los eclesiásticos Villavicencio, Durán Martel, Aspiazu y algunos clérigos; los que lo siguieron, en cuya clase se incluye toda la indiada; y los saqueadores, no incursos en los dos primeros delitos, pero que se aprovecharon del desorden para sus latrocinios." 
discernimiento" al respecto. Finalmente, el 27 de julio de 1812, con el consejo del fiscal Pareja, se fijó sentencia concediéndoles el indulto, apelando a la lógica de la minoría de edad -aunque esa calidad la había derogado los decretos de Cádiz-, respaldados por las órdenes del Virrey, establecidas el 1 de abril de $1812^{63}$.

En cuanto a los líderes de las montoneras, especialmente los alcaldes, tuvieron castigos diversos: los de los pueblos de Marias y Chuquis, fueron condenados a 10 años de presidio en el Callao; los de Panao, Santa María del Valle, Huacar, Acobamba, Chupán y Sillapata a 2 años de trabajos forzados en el socavón minero del Cerro de Yauricocha; y los demás, a la cárcel del Callao o a trabajos forzados en el socavón del Cerro de Pasco ${ }^{64}$. Sin embargo, Norberto Aro, recibió un tratamiento distinto, fue condenado al garrote, convirtiéndose en el único líder indígena al que se le dio la pena de muerte. Ahora bien, siguiendo la propuesta de algunos historiadores, esta condena singular, probablemente se explicaría por la asociación de su apellido con el líder Túpac Amaru II, reviviendo la memoria del caudillo de la más importante rebelión indígena, aplicándole este castigo con la finalidad de neutralizar este potencial recuerdo ${ }^{65}$.

Lo que ocurrió después de estas condenas, involucró pocos cambios porque no se destituyó a los subdelegados y las demandas principales no se cumplieron. Por el lado del Estado, lograron pacificar Huánuco, Conchucos, Huaylas y Cajatambo, retirándose el intendente Gonzales Prada, en octubre de 1812. Sin embargo, dejó una guarnición de cincuenta hombres armados en esta ciudad, debido a que el alzamiento produjo la imagen de que en cualquier momento se podrían reorganizar las montoneras, ya que la mayoría de sus integrantes fueron indultados, manteniéndose el miedo al retorno de la violencia por largo tiempo en

63 Sobre la minoría de edad: Marissa Bazán, La participación política de los indígenas durante las Cortes de Cádiz: Lima en el ocaso del régimen español (1808-1814) (Lima: Seminario de Historia Rural Andina/ Fondo Editorial Universidad Nacional Mayor de San Marcos, 2013), Capítulo III.

64 Véase: Joelle Chassin, "El rol de los alcaldes de indios en las insurrecciones andinas: Perú a inicios del siglo XIX”, 239.

65 Víctor Peralta, "La participación en las juntas de gobierno peruanas de Huánuco (1812) y Cuzco (1814)", 329. Otros líderes sentenciados a muerte fueron los criollos Crespo y Castillo y José Rodríguez, fusilados el 14 de setiembre en la plaza de armas de Huánuco. Para leer una breve biografía de los tres condenados a muerte revisar la cita 59 en: José Varallanos, Historia de Huánuco. Introducción para el estudio de la vida social de una región del Perú. 
la zona. De esta manera, si bien la rebelión fue derrotada, a casi un mes de su inicio, no la hace poco importante.

Finalmente, gracias a la perspectiva aplicada por esta investigación, para analizar a las montoneras rebeldes en Huánuco, que consideró a sus acciones como violencia ritual de carácter simbólico, nos ha permitido tener una interpretación de la forma de cómo se produjo la participación de los indígenas, durante el proceso de independencia, en su fase regional, superando la carencia de fuentes escritas, que motivaron a estudiar muy poco a este grupo social. Además, se puede afirmar que las montoneras buscaron dos objetivos: el primero, utilizar la violencia como vía rápida para lograr que se cumplan sus exigencias, como la caída de las malas autoridades y la mejora de su situación social y económica. Y lo segundo, demostrar -por lo menos simbólicamente-, a través de sus acciones, destacando los saqueos, la idea de que estaban logrando dicha "victoria". De allí, la puesta de su celebración con fiestas, bebidas, cánticos, proporcionando una expectativa de cambio y consiguiendo más reclutas comprometidos en mantenerse en pie de lucha y extender el levantamiento. En consecuencia, la violencia tuvo un sentido simbólico, bastante útil, derivado de su ritualidad e influenciada por experiencias previas. Si bien, es seguro, que algunos participantes carecieron de dicha perspectiva, una importante mayoría sí consideró a estas acciones violentas bajo dicha lógica. Por tal motivo, se entiende que los líderes de las montoneras direccionaron los saqueos y las fiestas, a la hora de capturar a los pueblos, siguiendo un mismo "modus operandi", como se ha descrito, a lo largo de este trabajo ${ }^{66}$.

Por consiguiente, se derrumban ideas como que las acciones violentas fueron producto de la barbarie y la falta de organización que llevaron al fracaso de la rebelión de Huánuco. Más bien, se debe considerar otras razones, incluso más poderosas, como fue la falta de armamentos y preparación suficiente porque los rebeldes eran civiles, una característica propia de las montoneras; el manejo inteligente de la contracampaña, liderada por el intendente Gonzales Prada y; sobre todo las dudas y traiciones de los sindicados como líderes criollos, destacando Berrospi y Crespo y Castillo ${ }^{67}$. Por tanto, la participación de las montoneras

66 Charles Walker, "La violencia y el sistema legal: Los indios y el Estado en el Cusco después de la rebelión de Túpac Amaru", en Poder y violencia en los Andes, eds. Henrique Urbano y Mirko Lauer (Cusco: CERABC, 1991), 138-139.

67 Ella Dunbar, "Prólogo", LIX; XXXVII-XXXVIII; Joelle Chassin, "El rol de los alcaldes de indios en 
que sostuvieron a esta rebelión, evidencia como las regiones actuaron, cuestionando las disposiciones políticas y económicas, sin necesariamente estar manipulados por los criollos, demostrando su propia lógica a la hora de llevar a cabo las acciones armadas, acompañados por sus líderes indígenas. Esto, demuestra una perspectiva regional activa que la historia oficial peruana debe darle mayor visibilidad, reconociendo su importante participación en la construcción del nuevo Estado, sin que con ello se disminuya el papel que tuvieron los ejércitos criollos, en el proceso de independencia de América Hispana.

\section{Bibliografía}

\section{Fuentes primarias}

Colección Documental de la Independencia del Perú (Tomo III) Vols. 1, 2, 3, 4, 5. "La Revolución de Huánuco, Panataguas y Huamalíes". Lima: Comisión Nacional del Sesquicentenario de la Independencia del Perú, 1975.

Nueva Colección Documental de la Independencia del Perú. Volúmenes 1, 2, 3, 4, 5. "La rebelión de Huánuco de 1812". Lima: Universidad Peruana de Ciencias Aplicadas (UPC), Congreso de la República, Fondo Editorial del Congreso del Perú, Asociación por la Cultura y la Educación Digital (ACUEDI), Fundación M. J. Bustamante de la Fuente, Red INTERINDI, 2018, http://www. acuedi.org/category?id=35 (15/08/2018).

\section{Fuentes secundarias}

Aljovín, Cristóbal. Caudillos y constituciones: Perú, 1821-1845. Lima: PUCP/Instituto Riva-Agüero / Fondo de Cultura Económica, 2000. Bazán, Marissa. "La participación de los sectores populares en la rebelión de Huánuco, 1812: Saqueadores, seductores e incanistas". Tesis de Magíster en Historia, UNMSM, 2017.

Bazán, Marissa. La participación política de los indígenas durante las Cortes de Cádiz: Lima en el ocaso del régimen español (18081814). Lima: Seminario de Historia Rural Andina/ Fondo Editorial Universidad Nacional Mayor de San Marcos, 2013.

las insurrecciones andinas: Perú a inicios del siglo XIX”, 239; José Varallanos, Historia de Huánuco. Introducción para el estudio de la vida social de una región del Perú, 483-492; César García, Dos precursores de la Independencia Nacional. 1805-1812, 66-72. 
Berroa, Francisco. Monografía de la Diócesis de Huánuco (1934). En Empresa periodística del Perú (Ed.), La revolución libertaria de 1812. Huánuco, 2012.

Bonilla, Heraclio y Karen Spalding. "La Independencia en el Perú: las palabras y los hechos". Lima, 2011, http://198.57.164.64/ ieporg/textos/DDT/peruproblema7.pdf (12/03/2017).

Calderón, Carmen. La insurrección de Crespo y Castillo del año 1812. Tesis de Doctorado en Historia, UNMSM, 1978.

Contreras, Carlos y Luis Miguel Glave (editores). La independencia del Perú. ¿Concedida, conseguida, concebida? Lima: Instituto de Estudios Peruanos, 2015.

Chassin, Joelle. "El rol de los alcaldes de indios en las insurrecciones andinas: Perú a inicios del siglo XIX”. Bulletin de I'Institut Francais d'Études Andines 1, N³7 (2008)

Demélas, Marie-Danielle. La invención política: Bolivia, Ecuador, Perú en el siglo XIX. Lima: IFEA, 2003.

Dunbar Temple, Ella. "Prólogo". Colección Documental de la Independencia del Perú 1 (III) Lima: Comisión Nacional del Sesquicentenario de la Independencia del Perú. I-XCVII, 1971.

Fernández, Baldomero. Huánuco en la revolución de independencia. Lima: Imprenta americana, 1938.

García, César. Dos precursores de la Independencia Nacional. 18051812. Lima: Editorial Minerva, 1973.

Geertz, Clifford. La interpretación de las culturas. Barcelona: Gedisa Editorial, 2003.

Glave, Luís. "Cultura política, participación indígena y redes de comunicación en la crisis colonial. El Virreinato Peruano, 1809-1814”. Historia mexicana LVIII (1). Julio-setiembre. México: El Colegio de México, 2008.

Mendez, Cecilia y Carla Granados. "Las guerras olvidadas del Perú: formación del estado e imaginario nacional" Rev. Sociol. Polít., Curitiba Vol. 20 No. 42 (2012) http://www.scielo.br/pdf/rsocp/ v20n42/06.pdf (28/06/2013).

Nieto Bonilla, Víctor. Control político, sectores sociales y la revolución de 1812. Lima: Fondo Editorial Cultura Peruana, 2004.

166 Ordoñez Salcedo, Sebastián. Los precursores olvidados. Gabriel Aguilar y Juan José Crespo y Castillo. Dos semblanzas en dos hechos históricos de la Emancipación. Lima, 1972. 
O’Phelan, Scarlett. "El mito de la “independencia concedida”: los programas políticos del siglo XVIII y del temprano XIX en el Perú y alto Perú (1730-1814)". Histórica Vol. 9 No. 2 (1985), http://revistas. pucp.edu.pe/index.php/historica/article/view/8222 (28/08/2016).

O'Phelan, Scarlett. Kurakas sin sucesiones: del cacique al alcalde de indios (Perú y Bolivia 1750-1835). Cusco: CERABC, 1997.

O'Phelan, Scarlett. "Abascal y el fantasma de las revoluciones". En Abascal y la contraindependencia de América del Sur, editado por Scarlett O'Phelan y Georgés Lomné. Lima IFEA/ Fondo Editorial PUCP, 2013.

Peralta, Víctor. "La participación en las juntas de gobierno peruanas de Huánuco (1812) y Cuzco (1814)". En Entre imperio y naciones. Iberoamérica y el Caribe en torno a 1810, editado por Pilar Cagiao y José María Portillo. España: Universidad de Compostela, 2012.

Roel, Virgilio. La independencia. Historia general del Perú. Lima: Edición del autor, 1988.

Thurner, Mark. "Guerra andina y política campesina en el sitio de La Paz, 1781". En Poder y violencia en los Andes, editado por Henrique Urbano y Mirko Lauer. Cusco: CERABC, 1991.

Tilly, Charles; Louis Tilly y Richard Tilly. El siglo rebelde, 1830-1930. España: Prensas Universitarias de Zaragoza, 1997.

Turner, Víctor. La selva de los símbolos. Aspectos del ritual Ndembu. Mexico: Siglo XXI editores, 1999.

Varallanos, José. Historia de Huánuco. Introducción para el estudio de la vida social de una región del Perú. Desde la época prehistórica hasta nuestros días. Buenos Aires: Imprenta López, 1959.

Vergara, Gustavo. Montoneras y guerrillas en la etapa de la emancipación del Perú, 1820-1825. Lima, 1973.

Vidal, Roger. La noche más larga de Huánuco: 22 de febrero de 1812. Huánuco, 2005.

Weber, Max. Economía y sociedad, $3^{\text {a }}$ ed. México: FCE, 2014

Walker, Charles. "La violencia y el sistema legal: Los indios y el Estado en el Cusco después de la rebelión de Túpac Amaru”. En Poder y violencia en los Andes, editado por Henrique Urbano y Mirko Lauer. Cusco: CERABC, 1991.

Para citar este artículo: Bazán Díaz, Marissa. "Montoneras andinas, violencia ritual y saqueos: el caso de los rebeldes de Huánuco (18111812)", Historia Caribe Vol. XV No. 36 (Enero-Junio 2020): 137-167 DOI: http:/ /dx.doi.org/10.15648/hc.36.2020.7 